\title{
Foreign Language Learning for the Visually Impaired in the Region of Central Macedonia, Greece: Problems and Suggestions
}

\author{
Christidou Sofia \\ University of Western Macedonia, Thessaloniki, Greece
}

\begin{abstract}
This article presents in brief the causes of visual impairment in modern times and sets the theoretical framework along with giving some practical tips of the teaching methods the teacher of foreign languages should follow in order to maximize the performance of the visually impaired students in the language classroom. Moreover, it presents a mini research held by the author in the area of Central Macedonia, Greece in order to trace the conditions which visually impaired students are faced with while learning English and other foreign languages in Greece and the problems that they are confronted with. Furthermore, through the elaboration of the questionnaires used in the research, some useful conclusions are drawn and some suggestions are presented about the improvement of the teaching of foreign languages to the blind and the measures the state should take.
\end{abstract}

Keywords: visual impairment, foreign language learning, questionnaire research, central Macedonia-Greece

\section{Introduction}

Vision problems encountered in various individuals may be due to genetic causes, childhood diseases, viral infections, brain tumors, injuries, or even transmitted diseases. These causes can bring on a number of types of visual disabilities, which vary as to the severity of the condition caused. Individuals with serious vision impairment face a number of difficulties which spread in many areas of their development process as integrated personalities. These areas are related to the kinetic development and their orientation, their social and emotional development, their linguistic development, as well as their cognitive development. Therefore, the educational process involving people with vision problems should not only play the role of a simple provider of knowledge and skills but should mainly function as a link which contributes to the understanding of the reciprocal interaction between the individual and the society that surrounds it.

Regarding the educational process, we can distinguish two main categories of vision impairment: low vision and blindness. The low vision students are usually users of printed educational material, but may require the use of additional equipment and materials. The extent of visual disability depends on the physical sensing attenuation of the student's eye, the age of the student at the beginning of the visual impairment, and the way that the attenuation occurred. The vision can also be variable or may be affected by other factors such as improper lighting, dazzling lighting, or fatigue. Therefore, there is no "typical" student with impaired vision problem. The

Christidou Sofia, Special Scientific Staff, Ph.D. in Translatology (Translation Criticism), Department of Mechanical Engineering, School of Engineering, University of Western Macedonia. 
major challenge faced by students with visual disabilities in the educational environment is the overwhelming number of visual materials to which they are continuously exposed through textbooks, school summaries, school programs, school boards, simply by writing, etc. Furthermore, the increased use of video, computers, compact discs, and television are added to the already large number of video materials to which the students have only limited access. Overcoming the students' optical limitation requires unique and personalized strategies based on the specific visual disability of each student and their ability to communicate (e.g., Braille, speed listening, etc.).

\section{General Behavior Guidelines for the Teachers}

Address the class when entering and leaving the class or site.

Call the students by their first names if you want to attract their attention.

Use descriptive words such as straight forward, left, right, etc., according to the orientation of the student's body. Be specific when giving directions and avoid using vague terms with inappropriate for use information, such as "there", "here", "this", etc.

Describe, in detail, the visual events related to the learning activities.

Describe and familiarize through the sense of touch the student with the classroom, the laboratory, equipment, supplies, materials, etc.

Provide verbal notification of possible class change, additional meetings, or activities.

Offer to read written information for a student with a visual impairment, where required.

Please mention your name, do not assume that a student with a visual impairment will identify you by the tone of your voice even if you have met before.

If asked to guide a student with a visual impairment, mention your name, offer your services and if they are accepted, offer your hand to the student's palm. Tell them if they need to ascend or descend stairs, tell them if the door is to their left or their right, and warn them of possible dangers.

Inform the student verbally whether you intend move or need to end a conversation.

If a student with a visual disability is part of your class, constantly control the learning environment to ensure that it is sufficient and ready for use.

When communicating with a student who has a visual impairment, always mention your name as well as the name of any other present in class.

Do not pet or touch a guide dog. Guide dogs are working animals. If the dog's attention is distracted, it may be dangerous for the person with a visual impairment.

Try to perceive the low noise produced by a portable brailler.

Use an audio signal or a tactile signal where normally an optical signal is used.

It is not required to speak loudly to people with visual impairment.

\section{Lesson Presentation by the Teacher}

By verbally spelling a new or technical word, you help the student with visual impairment, as well as the other students.

An enlarged text with activities, instructions, or reading a detailed course can be used by a person with impaired vision for the description of three-dimensional tactile models. 
Use an overhead projector to give instructions step by step. Cover all instructions except for the one you want to be followed.

Use an opaque projector whenever possible to zoom a text or a manual.

All colored objects used for identification and associated with a lesson, an experiment, or with other uses must be named with a Braille label maker or otherwise codified.

Describe, in detail, the visual events, the visual means, and the guidelines including all relevant aspects related to vision.

Use a narrator without any visual problems or a video with a verbal narration to describe the visual images of the videos or the compact discs. Describe in detail all the relevant visual events or the text which is written on the classroom board.

Where necessary, have the materials of the course written in Braille, or use an extended activity manuscript for classroom handouts.

Provide three-dimensional tactile models, paper with embossed lines or thermoform paper in order to complete drawings or graphs with a tactile shape when needed.

Whenever possible, use real objects (realia) in three-dimensional presentations.

Modify teaching to use listening or tactile presentation.

Use paper with embossed lines for temporary tactile presentations.

Allow students to use a tape recorder to record their presentations.

Modify all handouts and activities so that they are available in a suitable form, for example, normal printing, large scale printing, Braille, or audio recording, depending on how students communicate best.

\section{Teaching English to the Visually Impaired}

English language is part of foreign language learning in the educational system. Foreign languages have always been regarded as a demanding course intended for the most talented students. However, attitudes and methodology have changed and foreign language today is a subject included in the curriculum, as is the mandatory selection of a second foreign language, not only in Greek, but in schools all over the world. It is now widely accepted that the study of a foreign language is an important pillar in the education of students, providing both practical and professional benefits, as well as to the realization of a more comprehensive education. Additionally, the students themselves choose to learn a foreign language on their own, motivated by the chances for a more flexible professional mobility and increased opportunities for tourism, entertainment, and communication. For all these reasons, the great majority of students choose to learn English as their first foreign language, since now English is the language of trade and financial systems, as well as of the film and music industry.

The teaching of foreign languages to pupils with visual impairment presents some peculiarities and difficulties in relation to other subjects taught.

\section{The Transmission of Meaning}

A key feature of language teaching is that while in other courses communication is used to teach the course content, in foreign languages content is used to teach communication. The non-verbal methods of communication are key players in the teaching of meaning, while in most classes where languages are taught, vision plays a 
dominant if not an exclusive role. Consequently, the teachers of the visually impaired who are unable to use visual means to support their teaching, must look for new ways to facilitate the teaching of the target language without making compromises regarding the transmission of meaning.

\section{Means and Materials}

Today foreign language teaching is greatly based on vision. The meanings are often transmitted visually, using pictures, maps, and diagrams which are inaccessible to the visually impaired students. One solution is to prepare differentiated material which is though time consuming and costly. The students who use customized sources and material lose many physical-random learning opportunities and the chances to strengthen the incentives of the secondary information which is contained in the original material. In addition, students' opportunities to choose by themselves the readings which they find pleasurable are reduced.

\section{Reading and Writing Skills}

The difficulties in reading and writing in all subjects met by students with vision problems are commonly accepted, but are significantly increased in the case of learning a foreign language. The readers may have a particular difficulty with the handwriting of a foreign language. Another difficulty might be presented in the use of documents (catalogs, brochures, etc.) to be read which vary in font sizes, interpretation codes and sometimes present peculiar text arrangements. Moreover, stresses are often not so visible and should be highlighted.

The Braille users follow a more unified system, with different types of difficulties. Each language has different abbreviations. Despite the use of the first degree Braille for foreign languages in order to include symbols for stresses and symbols for common words, a risk of confusion still remains. Students from a point and on will have to either learn to use the Braille code of the foreign language, which requires a very good command of the Braille code of their mother tongue to avoid confusion, or to work with recordings.

\section{Access to Reference Material}

A particular point of difficulty for students with visual impairment is their effective access to dictionaries whose use is a major problem for both printed text users and Braille users. Volunteer readers can be a solution to this. In this case, however, the use of the dictionary is a troublesome dependence on others for the students and is not a skill of the student. Talking computers and mobile signs in Braille can help, but what is really needed is a complete and effective talking pocket dictionary with good pronunciation.

\section{Use of Information Technology Where Appropriate}

Despite the students' with visual impairments relative familiarity with the use of computers, the commercially available software for language learning is mainly visual. The sound synthesis systems available for text editing vary in capacity to produce foreign languages and mobile Braille signs are expensive. CD-ROMs can provide reading materials with sound, but when it comes to its selection, teachers should make sure that the visual elements are not the dominant ones.

\section{Assessment Procedures}

Reading comprehension during an assessment may be a big test for the memory since the student does not have the opportunity to keep notes in order to be helped. The additional time given to the students as to complete the examination is necessary, but it puts to test their physical endurance and their ability to concentrate. 


\section{Foreign Language Learning Practices for People With Vision Impairment}

It is obvious that the main challenge in foreign language learning for people with vision problems is to reduce the importance of the element of visual representation without affecting the transmission of the meaning. This can be achieved by introducing a limited number of vocabulary and ideas, using tactile objects, the sense of smell or taste, and sound effects, but care must be taken so that all students fully understand what they experience, which in a relatively numerous class might not be possible. Moreover, the use of objects, relief maps, charts, and all kinds of recorded sounds is advisable.

It is generally accepted by most teachers that, for the transmission of the meaning of foreign words, they use their mother tongue more than they would like to. One suggestion would be the "code change" until the students gain an initial level of understanding. The method to achieve this is to use the target language first, repeat the word in their mother tongue and then again in the target language. Gradually the support of the mother tongue is withdrawn as the students will begin to learn the meaning of each word. The disadvantage which can result from this method is the confusion created regarding the continuous and alternating use of different languages.

Inevitably, when it comes to students with visual impairments, more emphasis is laid on acoustical stimuli.

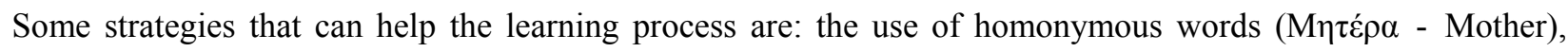
speaking clearly, emphasizing on already known words and the tone of voice. A student may also be asked to explain something to the whole class. Controlling comprehension in this way is necessary to avoid verbalism, which is the use of words and phrases without fully understanding their meaning.

Another approach to teaching students with visual impairment supports the use of physical expression to help speak in the foreign language. Role plays and dramatized dialogues not only help students to develop orientation and mobility skills, but also help them put to use the language of a particular meaning and practice linguistic expressions. An active and multisensory approach is encouraged in this way. Learning and reciting simple songs or poems or encouraging the students to create improvised rhyming lyrics and songs can also be very helpful.

Finally, another feature that enhances the motivation of the students and supports understanding by giving meaning to learning is to negotiate the content of learning. This will inevitably be done in the students' mother tongue and since in this way students fully understand what are learning, the advantages outweigh by far the disadvantages of the use of the mother tongue.

\section{Presentation of Programs for Teaching English to Adults With Sight Problems Abroad and in Greece}

\section{Project "Listen and Touch: A Basic English Course for the Visually Impaired"}

The project "Listen and Touch" started on October 1, 2002 and was funded by the European Commission Program Socrates (Action Lingua 2: Development of tools and teaching materials) and aims to meet the needs of young adults who are blind or visually impaired to learn foreign languages and particularly in learning English as a foreign language.

The directions of the program are, on the one hand, the development of foreign language teaching methodology for blind people, and on the other, the realization of 2-level English courses, which will be based on the adaptation of a successful course for foreign language teaching to a comprehensible Braille format enriched with special didactic materials. 
The next steps of the program include the publication of the Braille lessons which will be implemented in the three pilot institutions cooperating in the project (Austria, Greece, and Bulgaria) from September to October 2003. A review of the pilot program participants (teachers and blind students) is also expected, as well as evaluation reports from the participating institutions.

Project Partners:

Euroinform Ltd. (Bulgaria): project coordinator.

School for the Blind of Northern Greece "Helios": institution for the education of the blind and visually impaired in Northern Greece.

Bfi Steiermark (Austria): one of the most important institutions of the Austrian adult education.

Rochester Independent College (England): educational institution that provides GCSE, beginner lessons, and courses of English as a foreign language, covering a wide variety of needs.

Virtua Ltd. (England): company which specializes in the research, design, and production of teaching materials for people with disabilities.

National Association of Blind Entrepreneurs: Bulgarian organization that provides training, career guidance and social rehabilitation for people with visual impairment.

\section{Kaizen Program for New English Learners With Visual Limitations, USA}

The Kaizen program was formed in 1998 and is a small non-profit organization in Seattle, USA, specifically devoted to helping blind and visually-impaired immigrants and refugees who need to learn English.

The program works mainly with volunteer teachers trying to use the material and know-how provided by the existing organizations dealing with visually impaired people and organizations involved in teaching English as a foreign language. The institution St. James, with which the Kaizen program has a close cooperation since 2002, falls in the latter category.

The program's main mission is to help blind and visually impaired immigrants and refugees obtain the competencies and information they need to communicate in English, make decisions, take appropriate action, advocate for themselves, become functionally literate in accessible formats, obtain personally fulfilling, dignified employment, and lead independent lives.

For this purpose, a training program that includes the most effective ways to assist the students in learning and practicing reading and writing has been developed. Moreover, members of Kaizen staff produce citizenship application forms and other citizenship materials in Braille and large print, and then distribute them to public libraries and other places where regular print versions of this material are generally available. They staff of Kaizen have also prepared a basic citizenship course in simplified English which does not depend on visuals for teaching and learning. Finally, Kaizen inform mainstream programs more systematically about these efforts and encourage wider use of the adapted materials produced.

\section{Scottish Sensory Centre}

It works under the auspices of the Moray House School of Education which is engaged in the training of trainers and research in Pedagogy and the University of Edinburgh. It is addressed to everyone who is involved in the education of deaf children and visually impaired children and young people, the young people themselves and their families. 
The Scottish Sensory Centre offers a series of training courses for adults with visual impairments such as Braille code, development of visual skills, mobility issues, independent living skills, and research on creativity's role in higher education. It also provides a series of seminars for the student's parents which assist them in playing an essential role in the educational and social advancement of their children.

\section{Project "Portfolio for the Blind"}

The project "Portfolio for the blind" is done by the "School for the Blind of Northern Greece 'Helios"” and is part of the European Language Portfolio.

The European Language Portfolio is addressed to any person who wants to certify his/her level of language proficiency within the EU and consists of three parts: the Language Biography, the Language Passport, and the Dossier. The portfolio certifies the level of language proficiency of a person through scales certified by the European Union. This scaled classification is the result of certain descriptors which define the level of language proficiency in terms of qualifications or in terms of language skills that have been acquired by non-formal education. It is personal and individualized, and the user may state as many languages he/she has command of, where he/she has learnt them, what is his/her level of each specific field of language (writing, speaking, etc.). It also provides the opportunity to organize their personalized learning strategy, i.e., by choosing which language and which skill they should focus on in order to achieve the results they wish. This will determine the learning material which will be provided. There is also the possibility of continuous update of the portfolio based on the new cognitive skills to be acquired, and thus the user can determine the next learning objective. The user, apart from degrees and language certificates, can also include the portfolio visual and sound documents (e.g., video conferences) so that an eventual employer might have a complete picture of the user's language level.

The "Portfolio for the Blind" is an electronic language portfolio, in which the descriptors have been adapted by a number of linguists from Greece, Bulgaria, and England and is addressed to people with visual impairments, and based on these the electronic file becomes accessible (it can work with a screen reader, it can printed in Braille, etc.). The project started in 2008 and is almost in the final phase (feedback phase). The pilot implementation of the project is expected to be around June 2009. The final version will go through a certification process by the European Union and will be the official website of the European Language Portfolio.

\section{Questionnaire Answered by Visually Impaired People Regarding English Language Teaching}

\section{Creation of the Questionnaire}

The research was conducted on a sample of 12 individuals, four of which were men and eight women. The age range varied from 13 to 53 years old. Six of the participants in the research have partial vision loss, five total loss of vision while one person does not have vision problems. For the creation of the questionnaire we created three forms (see Appendix). The first one explores problems met and proposals made by visually impaired individuals who have learned English as a foreign language; the second one presents some additional questions addressed to visually impaired people who have taught English and the third to sighted teachers who teach foreign languages to people with visual impairments. The number of participants did not play a leading role in 
this research. Instead, we regarded as more important to cover of a variety of cases of people involved in foreign language learning in terms of gender and age, and in terms of visual impairment. In this way we were able to study the process of foreign language learning over time, as well as any development steps. Moreover, we chose open type questions, which are more difficult to process and to draw conclusions, because we think that all participants are unique, both in terms of the problem they experience and in general their course of life, the experiences regarding the aim of the research, and the suggestions they may make. Therefore, we believe that this small and uneven, but illustrative of the situation we are trying to describe, sample of individuals would not have been properly utilized with a closed type questionnaire. Finally, we would like to thank those who volunteered to contribute to this research which we believe will help to draw useful conclusions about the state of English language teaching to people with sight problems in Greece and to what can be done to have better results in the future.

\section{Research Conclusions}

Nowadays people with visual impairment do not live isolated from their social surroundings and therefore come into contact either through their work or through other activities carried out with people from other countries or they travel to foreign countries either for health related reasons or for personal or professional purposes. Consequently, learning one or more foreign languages is a priority for students and adults with visual impairments who want to acquire a skill which will assist them in their professional career and their personal activities.

If one takes the Greek educational reality into account, where in recent years the model of parallel support is promoted in secondary education and particularly in the so-called "special" schools where various categories of people with disabilities are educated together in one class, it is obvious that parallel support should be extended in the foreign language courses which are included in the national curriculum by providing a foreign language teacher specialized in visual impairment. Since vision problems vary and should be treated with a different curriculum each, the foreign language teacher should, beyond any support offered to the student to address the range of his/her needs in the foreign language, develop an individual program linked to the exact vision problems faced by the student. This program will include the creation of specially adapted material, for example large print texts, scanning of documents and subsequent conversion in Braille texts for people with total vision loss who know Braille, texts in electronic format for Text Reader programmes for those who have the necessary skills to use a computer, etc. The ideal scenario would be to have a special teacher placed in the classroom along with the foreign language teacher but even the simple form of parallel support is a positive step towards a more direct access to the education system of people with vision problems.

Regarding foreign language teaching to adults with vision problems, apart from the proposals made above for the education of students which should also be applied to adults, we must also acknowledge the fact that for the creation of an individualized syllabus by the teacher the specific time during which the vision problem of the adult student came up is of great importance. If the students have a visual impairment since birth, they will probably be familiar with the Braille code as well as with other educational methods for people with visual impairments. Therefore, the material used by the instructor can be compatible with that used in the education of underage students. However, if the vision problem has arisen at a later stage of the students' life, then the instructor should investigate whether they have mastered any teaching methods for the visually impaired, as they 
may have received all their training as sighted individuals. In this case they will have memories of visual images and know the usual way of teaching in a class. Moreover, they have the same perceptions with a sighted person. In this way, they will already share a code of communication with their trainer, which can be used to overcome difficulties in the understanding of basic meanings (colors, shapes, objects) which are widely used in foreign language teaching. On the other hand, there is a possibility that they may find it hard to work with the adapted material given and teaching methods applied, depending on their degree of familiarity with the technologies and materials used to help people with vision problems learn. In this case they should be mostly given audio material since this is a familiar way of learning before they acquire the visual impairment. Another issue to consider is the level of knowledge the adult people already have in a foreign language. This can work positively for them by helping them to further advance in learning the foreign language, since if they already know basic linguistic, grammatical, and syntactic structures and knowledge, further teaching may include some higher cognitive skills of the language they are learning. On the other hand, existing knowledge may hinder learning in cases where the adult, having become accustomed to the visualized way of learning a language, cannot adapt to the new way of teaching and faces problems in memorizing and understanding of new terms and meanings. Finally, we must not forget that when talking about adults, we are dealing with people where the absorption rate of the things taught is quite lower than in minors. Moreover, the use of new technologies and specialized teaching methods necessary for teaching people with disabilities may obstruct adult education since their adaptability to new ways and behaviors is limited if not impossible. Therefore, in order to achieve the best possible results, it would be essential to have adult students, before the start of the teaching program, complete a questionnaire and then use it to gather information necessary for the proper development of the materials to be used and the selection of teaching methods to be followed.

Additionally, according to the answers to our questionnaire, older visually impaired people regarded learning a foreign language as something extremely difficult. This impression was instilled in their minds first by their environment where foreign language lessons were considered secondary and only for very smart students, and secondly because of the "embryonic" state of the educational material, the lack of computers and other electronic devices used to read and write, and because of the grammatical method used not only in foreign language courses, but in all subjects. However, as the age of the participants decreases, we see a steadily increasing ease to learn foreign languages, even the acquisition of higher education degrees, with several difficulties, however, mainly due to the lack of material and infrastructure of the universities and due to the failure to adapt the existing curriculum to the specific needs and demands of the visually impaired. Finally, regarding the new generations who attend now secondary schools we might say that, through the infrastructures available and the existence of special classes in schools, foreign language is no longer considered as the hardest subject, but, on the contrary, one of the easiest ones.

One other point which was made clear by the interviews we made is the great importance of the relationship between a person with a visual problem and his/her instructor. Trainers who build a strong sense of trust and friendship with their trainees get much better learning outcomes than those who do just their job. This is easily understood, since people with low vision need to have, to a greater extent compared to the sighted ones, a sense of safety, confidence, and a positive mood in order to initially work in a group and then present progress in their studies. 
Another observation we can make is that people with vision problems gradually become more active members of the society they live in and participate in many activities apart from their professional ones; they develop their personality and get in contact through sport, music, or even over the internet with people from other countries. In this effort, knowing one or more foreign languages becomes an important tool and a necessity that cannot be ignored. Hence, they consider this knowledge a priority, regardless of their educational level and social profile.

\section{Conclusion}

As one can see there is still a long way for the Blind to get their rightful place in the Greek educational system especially nowadays that Greece is facing a deep economic crisis. We should mention the great differences in the supportive infrastructures which people with visual impairments get from the state and the society in general which vary according to their place of residence. While we recorded multilevel support to people living in Thessaloniki (tutorial classes of the School for the Blind, special primary school, Printing in Braille, Parallel classes in schools, parallel support to general classes, etc.), the situation experienced by people living in the provinces is disappointing. People with vision impairment do not get any support; both themselves and their parents are literally abandoned, and are unable to solve even the simplest of their problems (e.g., access to school buildings). The situation deteriorates day after day since financial support towards special educations is constantly reduced due to the financial crisis. Competent state institutions should be concerned with this issue straight away and we propose the creation of an official body of some kind, at least one for every prefecture, which will try to take and coordinate actions to solve the fundamental problems that these individuals face.

\section{References}

Aiazzi, A. (2008). Teaching English to blind and visually impaired pupils. Retrieved from www.hltmag.co.uk/jan08/stud02.rtf

Kashdan S., \& Barnes, R. (2004). Teaching English as a new language to visually impaired and blind ESL students: Problems and possibilities. Retrieved from www.afb.org/info_document_view.asp?documentid=1933

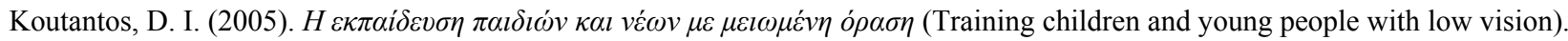
Athens: Ellinika Grammata Publications.

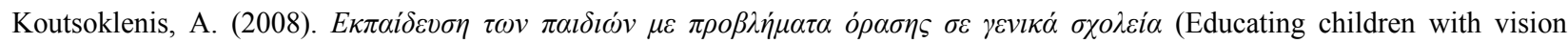
problems in regular schools). Notes of Specialization Program, Thessaloniki.

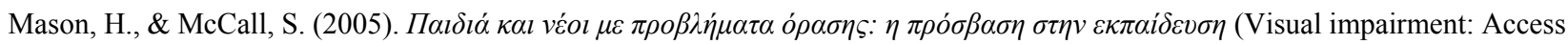
to education for children and young people). Athens: Ellinika Grammata Publications.

Michell, E. (2007), Teaching English to the visually impaired. Retrieved from http://www.nytimes.com/2007/11/21/nyregion/21neediestsidebar.html?_r=1

Papadopoulos, K. (2005). Tú $\varphi \lambda \omega \sigma \eta \kappa \alpha \iota \alpha v \alpha ́ \gamma v \omega \sigma \eta$ (Blindness and reading). Thessaloniki: Zitis Publications.

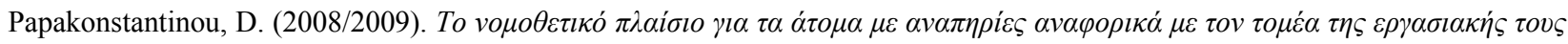
$\alpha \pi \alpha \sigma \chi \delta ́ \lambda \eta \sigma \eta \varsigma$ (The legal framework for people with disabilities in relation to their field of employment). Notes of Specialization Program, Thessaloniki.

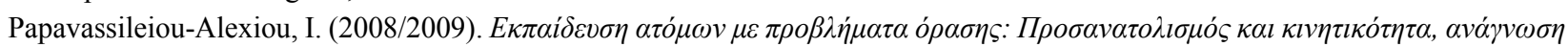

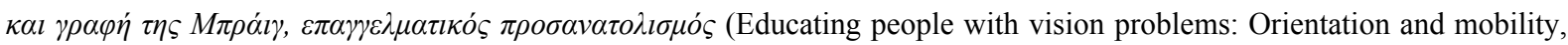
Braille reading and writing, professional orientation). Notes of Specialization Program, Thessaloniki.

Reese, S. (2006). When foreign languages are not seen or heard. The Language Educator, 32-37. Retrieved from bit.ly/1A4X0o5

Seng, C. (2004), Teaching English to blind students. Retrieved from http://www.teachingenglish.org.uk/think/articles/teaching-english-blind-students 


\section{Appendix: Questionnaire Samples}

\section{Questionnaire for Visually Impaired Students Attending Secondary Schools Regarding the Subject of English Language}

\section{Demographics:}

Sex:

Age:

Level of education:

Vision impairment assessment:

Other comments:

\section{Professional experience:}

1. Where do you learn the English language? (school, private lessons)

2. If you learn English at school do you have any learning problems in relation to your classmates?

3. What kind of infrastructures does your school provide?

4. Do you face any problems regarding the infrastructures? Do you have any suggestions?

5. Do you experience any problems with your teachers' teaching methods?

6. Do you experience any particular difficulty in the subject of English compared to the other subjects?

7. Do you have any suggestions to make regarding the way you are taught the lesson of English language?

8. To what extend do you use the foreign language that you know in your everyday life for communication?

\section{Questionnaire for English Language Teachers With Visual Impairment}

\section{Demographics:}

Sex:

Age:

Level of education:

Vision impairment assessment:

\section{Secondary education experience:}

1. What kind of school did you attend? (special, regular...)

2. What kind of problems did you experience with your classmates?

3. What kind of problems did you experience with the infrastructures?

4. What kind of problems did you experience with the support provided by your teachers?

5. Were you instructed by your teacher to follow a particular strategy for the lesson of English language different from the other subjects?

6. Do you use in your current educational practices any of the things you learned as a student in secondary education?

\section{University studies experience:}

1. Where did you get your university degree (country, name of university)?

2. What kind of problems did you experience with your fellow students?

3. What kind of problems did you experience with the infrastructures of the university?

4. What kind of problems did you experience with the support provided by your professors? 
5. Was the educational process (lectures, projects, exams etc.) conducted in such a way to keep up with your particular condition and how?

6. How would you evaluate this process? Mention any positive or negative elements and make suggestions for its improvement.

7. How do you evaluate the functionality and usability of the institution's library regarding your particular condition (positive or negative elements, possible suggestions)?

8. Have you received any particular education regarding teaching English to people with special needs?

\section{Experience from your professional activity:}

1. Have you ever taught in a class or given any private lessons?

2. Do you see any differences in your teaching methods?

3. Mention any negative and positive points of your professional experience.

4. Which of the teaching practices for people with visual impairments that you have been taught or applied in a class helped the whole class, which ones helped some students to overcome their difficulties individually and which, based on your professional experience, are ineffective or harmful to the learning process and why?

5. Do you think that the learning process in the lesson of English language for people with visual impairments presents particularities compared to the other subjects taught to the same students? If yes, which are those and how do you deal with them?

6. Have you used different teaching practices and approaches to people with different visual problems? Is yes, which are these practices and approaches and for which categories of visual impairments? If not, why?

7. Which are the particularities of a class with visually impaired people compared to a regular English class? (State briefly)

8. Can you say if the students' character or behaviour assisted or obstructed the learning process? Which teaching methods did you use to overcome any possible problems?

9. Were you provided with any teaching material?

10. Was it sufficient? If not, suggest any points which need improvements or other points where the material should be replaced. Please, say how these improvements will be made.

11. Have you spotted any differences regarding the education process and outcome compared to your colleagues who do not have any vision problems? If yes, which ones?

12. Finally, based on your educational experience, please, mention anything you consider important regarding teaching English to visually impaired people and hasn't been touched by the questions above.

Thank you!

\section{Questionnaire for Sighted Teachers of Foreign Languages}

\section{Demographics:}

Sex:

Age:

Level of education:

Professional experience:

University studies experience:

1. Where did you get your university degree (country, name of university)?

2. Have you received any particular education regarding teaching French to people with special needs? 


\section{Special education for teaching to people with vision problems:}

1. Have you had any specialized training for teaching to people with special needs?

2. If yes, by which institution, for how long and what kind of courses did you attend?

3. Based on your subsequent professional experience how would you evaluate the training received (positive and negative points, possible suggestions)?

\section{Experience from your professional activity:}

1. Have you ever taught in a class or given any private lessons to people with vision problems? If yes, please answer the following questions.

2. Do you see any differences in the teaching methods you applied in a class and those in private lessons?

3. Please, mention any positive or negative aspects of each case.

4. Which of the teaching practices for people with visual impairments that you have been taught or applied in a class helped the whole class, which ones helped some students to overcome their difficulties individually and which, based on your professional experience, are ineffective or harmful to the learning process and why?

5. Do you think that the learning process in the lesson of French language for people with visual impairments presents particularities compared to the other subjects taught to the same students? If yes, which are those and how do you deal with them?

6. Have you used different teaching practices and approaches to people with different visual problems? Is yes, which are these practices and approaches and for which categories of visual impairments? If not, why?

7. Which are the particularities of a class with visually impaired people compared to a regular French class? (State briefly)

8. Can you say if the students' character or behaviour assisted or obstructed the learning process? Which teaching methods did you use to overcome any possible problems?

9. Were you provided with any teaching material?

10. Was it sufficient? If not, suggest any points which need improvements or other points where the material should be replaced. Please, say how these improvements will be made.

11. Have you spotted any differences regarding the education process and outcome compared to your colleagues who have vision problems? If yes, which ones?

12. Finally, based on your educational experience, please, mention anything you consider important regarding teaching French to visually impaired people and hasn't been touched by the questions above.

Thank you! 